Revue

Revue de l'histoire des religions

de Ihistoire des religions

1 | 2014

Varia

\title{
André Vauchez (dir.), Prophètes et prophétisme
}

Paris, Éditions du Seuil, 2012

Bénédicte Sère

\section{(2) OpenEdition}

Journals

Édition électronique

URL : http://journals.openedition.org/rhr/8202

DOI : $10.4000 /$ rhr.8202

ISSN : 2105-2573

Éditeur

Armand Colin

Édition imprimée

Date de publication : 1 mars 2014

Pagination : 120-123

ISBN : 978-2200929107

ISSN : 0035-1423

Référence électronique

Bénédicte Sère, "André Vauchez (dir.), Prophètes et prophétisme », Revue de l'histoire des religions [En

ligne], 1 | 2014, mis en ligne le 13 mai 2014, consulté le 22 septembre 2020. URL : http://

journals.openedition.org/rhr/8202 ; DOI : https://doi.org/10.4000/rhr.8202

Ce document a été généré automatiquement le 22 septembre 2020.

Tous droits réservés 


\section{André Vauchez (dir.), Prophètes et prophétisme}

Paris, Éditions du Seuil, 2012

\section{Bénédicte Sère}

\section{RÉFÉRENCE}

André Vauchez (dir.), Prophètes et prophétisme, Paris, Éditions du Seuil, 2012, 475 p., $24 \mathrm{~cm}, 23,50 €$, ISBN 978-2-02-102820-1.

1 Parce qu'il avait tant travaillé sur la sainteté depuis les années 1980, André Vauchez a voulu passer à l'histoire du prophétisme dont il est aujourd'hui un des meilleurs spécialistes français. Le domaine, largement négligé par l'historiographie française, a ressurgi dans les années 1960 grâce au livre de Norman Cohn, Les fanatiques de l'Apocalypse (1957). Les Européens et les Anglo-Saxons, notamment avec leur Encyclopedia of Apocalypticism (2000), se passionnent pour le sujet. C'est à leur contact qu'André Vauchez éprouve l'envie de s'atteler à l'édition du Liber Ostensor de Jean de Roquetaillade, entreprise collective de plus de quinze ans qui aboutit en 2006. Il publie aussi une série de mélanges de l'École française de Rome et, en 2011, écrit L'Intuition prophétique en collaboration avec Sylvie Barnay, laquelle vient de faire paraître une anthologie de textes prophétiques, La parole habitée. Les grandes voix du prophétisme. C'est donc bien en écho à ce recueil de textes qu'il faut lire l'ouvrage collectif dirigé par André Vauchez.

2 Le livre est traversé d'un souffle. Son sujet, Prophètes et prophétisme, pouvait le laisser prévoir. Transpériodique et transcontinentale, cette fresque de l'histoire du prophétisme offre une galerie de portraits, d'Isaïe à Martin Luther King et Etty Hillesum en passant par Joachim de Flore, Nostradamus, ou encore Charles Péguy, Yves Klein pour ne citer que les plus célèbres. Une fresque qui offre surtout une réflexion sur le prophétisme comme objet d'histoire. En effet, dans une veine très certalienne, les historiens du volume n'ont pas craint d'ériger le discours prophétique en objet 
d'histoire. Sorte de fable prophétique, le livre est un essai pour penser le prophétisme à l'aune de la chronologie historique, dans les contextes d'émergence qui suscitent les prophètes, en prenant la mesure de la réception des discours prophétiques et des mutations sémantiques du qualificatif. Le "prophétique ", en effet, oscille entre le mystique et le spirituel, d'une part, l'apocalyptique, l'eschatologique, le messianique voire l'utopique, d'autre part. Or, l'approche ici présentée rend précisément compte d'un processus historique de la définition même du terme, au fil des périodes et des aires culturelles.

3 Pierre Gibert, dans une première partie, prend le concept à ses origines bibliques en en questionnant le vocabulaire dans ses traductions: nabi devient prophètès dans la Septante, pour signifier que le prophète biblique est porte-parole et interprète plus que messager. À partir de là, l'auteur esquisse quelques traits de définition : le prophète est " instance correctrice", « observateur critique de moments historiques", «fondateur du monothéisme » qu'il aurait contribué à créer plus qu'il n'en aurait été le défenseur. Il distingue deux prophétismes dans l'histoire d'Israël : un prophétisme de malédiction relayé par un prophétisme de consolation, à la manière du deutéro-Isaïe.

4 André Vauchez enchaîne, dans une seconde partie, sur le prophétisme chrétien, de l'Antiquité tardive à la fin du Moyen Âge. Ce qu'il pointe tout au long de la période médiévale, c'est la tension entre le pôle prophétique et le pôle institutionnel: dans l'Antiquité tardive et le haut Moyen Âge, le prophétisme est marginalisé au rythme de l'institutionnalisation de l'Église qui affirme le pouvoir des anciens et des responsables, presbytes et évêques. Toute forme de pneumatisme ou de parole inspirée est reléguée au second rang et après Augustin, le prophétisme, assimilé à la prédiction, devient ainsi plus intellectuel qu'émotionnel. D'où la définition: «le prophète est celui qui, parce qu'il voit et comprend avant tout le monde les choses obscures, peut annoncer l'avenir à ses auditeurs ou à ses lecteurs ». Le monachisme devient alors la modalité ecclésiale du prophétisme face à un clergé séculier qui signifie la cléricalisation de l'Église et son plus pur produit s'incarne dans la figure de Joachim de Flore, « le personnage le plus important dans l'histoire du prophétisme médiéval ", le dernier tenant de l'exégèse monastique pour qui les seuls hommes vraiment "spirituels" sont les moines, cette contre-société, pierre d'attente d'une cité future. Les croisades ensuite donnent un souffle à l'esprit prophétique tant il est vrai, comme le montrait déjà Alphonse Dupront, qu'elles portent en elle cette indéniable composante messianique. Sur la fin du Moyen Âge, dans le contexte de troubles religieux et politiques, le prophétisme devient l'arme, sinon de la contestation, du moins de la critique politique. Il se politise, se multiplie et se féminise. Les avertissements s'adressent aux détenteurs de l'autorité, qu'ils viennent, entre autres figures, de Pierre de Jean Olieu, Brigitte de Suède, Catherine de Sienne, Jean de Roquetaillade, Télesphore de Cosenza, Jeanne d'Arc ou François de Paule...

5 Dans une troisième partie, Jean-Robert Armogathe reprend le récit au $\mathrm{Xv}^{\mathrm{e}}$ siècle : il y traite de la figure sulfureuse et exaltée de Savonarole pour en faire un prophète rebelle et martyr, dont les flammes même de son bûcher n'arrêteront pas la diffusion de la parole, relayée par ses disciples notamment. Puis viennent les portraits de Christophe Colomb, des grands réformateurs luthériens, calvinistes et catholiques, d'Antonio Vieira, de Nostradamus, transformé en archétype du mage, sans oublier les disciples des Lollards en Grande-Bretagne, les prophètes d'Europe Centrale dans la tourmente de la guerre de Trente Ans, les prophètes camisards cévenols et les prophètes des 
jansénistes persécutés. Ce qu'il souligne, dans cette partie, c'est l'essence foncièrement apocalyptique du christianisme: "il faut donc se garder de ramener le discours prophétique aux seuls mouvements extrémistes, et d'en faire l'expression de minorités en révolte » (p. 130). Philippe Boutry narre le prophétisme de la Révolution à la Grande Guerre (1789-1914), dans ce contexte de mutation où le XIX $x^{e}$ siècle est en proie au choc de toutes les modernités. Égrenant, de manière presque litanique, une multitude de portraits prophétiques, tant croyants que rationalistes ou athées, protestants que catholiques, Boutry pointe le paradoxe d'" une onde prophétique puissante et inédite " qui parcourt et bouleverse un monde qui se veut positiviste et scientiste. Sylvie Barnay, enfin, relève le défi de disserter sur le prophétisme au $\mathrm{xx}^{\mathrm{e}}$ siècle, en Europe. Ses analyses conduisent à une conclusion majeure: le prophétisme du $\mathrm{xx}^{\mathrm{e}}$ siècle est sécularisé. D'où sa traversée de tous les champs culturels : la littérature avec Péguy et Claudel qui nous disent à quel point « l'écriture poétique est le mode de la prophétie ", l'histoire de l'art avec Magritte, Malevitch ou Yves Klein, la politique dans sa forme la plus idéologique (Hitler et le III ${ }^{e}$ Reich) et dans ses plus profondes résistances (Walter Benjamin, Gershom Sholem, Martin Buber, Etty Hillesum...), la philosophie et la théologie dans leur effort pour théoriser le prophétisme (Emmanuel Mounier, Paul Ricoeur et, dans la mouvance de Vatican II, Yves Congar). En trois parties finales, le prophétisme $\mathrm{du} \mathrm{xx}^{\mathrm{e}}$ siècle est décliné dans son étude historique en Afrique noire (Valerio Petrarca), en Amérique latine (Jean-Pierre Bastian) et en Amérique du Nord (Isabelle Richet).

6 Ce qui semblerait donc fonder la spécificité du prophétisme en tant qu'il est érigé en objet d'histoire, c'est bien une modalité propre de son intervention a priori anhistorique au sein même des situations de crise, de son impact dans le cours de l'histoire. Pour le dire autrement, le propre du prophétisme, à la lecture de l'ensemble des contributions du volume, semblerait se jouer dans l'articulation des trois modes de la temporalité : passé, présent, futur. Le prophétisme est une manière particulière de conjuguer les trois temps : relecture du passé, défrichement du présent, prédiction de l'avenir. Plus précisément, il se love au creux de la tension entre le « déjà » et le " pas encore ». Il entrelace sans les perdre les fils des trois temps : il n'est pas de présent sans futur, ni de futur sans présent, ni de passé idéalisé, encore moins de passé répété. Comme l'écrit Sylvie Barnay, «le temps de la prophétie semble plutôt celui du futur antérieur, [...] qui opère la métamorphose du futur en antérieur et de l'antérieur en futur, établissant que le verbe soit dit pour toujours» (p. 346). Par la puissance poétique de son écriture et le jeu sur la triple temporalité, le prophétisme se mesure historiquement comme « un pouvoir opératoire sur le temps présent qui en fait une composante irremplaçable des forces de l'histoire » (p. 198). Après la lecture du volume, les prophètes se révèlent des acteurs décisifs de l'histoire par leur marginalité et leur anticonformisme foncier. Mieux, ils s'avéreraient presque les seuls de leurs contemporains à vivre en profondeur leur époque, "êtres d'incandescence", "déchireurs d'horizon", "race vibrante et gênante" qui "dérangent, avec une insupportable lucidité, les hommes qui vivent en surface et les institutions qui s'enlisent » (Gérard Bessière). 


\section{AUTEURS}

\section{BÉNÉDICTE SÈRE}

Université Paris Ouest - Nanterre La Défense 